New Synt het i c Met hodol ogy towar d

Nacr ol i des/Mecr ol act ans vi a

Pal I adi um Cat al yzed Car bon- Het er oat om Bond- For ming React i ons

\begin{tabular}{|l|l|}
\hline 著者 & $\begin{array}{l}\text { Yoda H dem, Sengoku Tet suya, Hanamat su } \\
\text { Tonøya, I nuzuka Toshi yasu, Takahashi Nasaki }\end{array}$ \\
\hline $\begin{array}{l}\text { j our nal or } \\
\text { publ i cat i on t i t l e }\end{array}$ & Synl et t \\
\hline vol une & 2011 \\
\hline number & 12 \\
\hline page range & $1766-1768$ \\
\hline year & $2011-07$ \\
\hline 出版者 & Thi eme \\
\hline 権利 & $\begin{array}{l}\text { C) Geor g Thi eme Ver I ag St ut t gart ? New York . } \\
\text { uww. thi ene- connect . com }\end{array}$ \\
\hline URL & ht t p: //hdl . handl e. net /10297/6749 \\
\hline
\end{tabular}




\title{
New Synthetic Methodology toward Macrolides/Macrolactams via Palladium-Catalyzed Carbon-Heteroatom Bond-Forming Reactions
}

\author{
Tetsuya Sengoku, ${ }^{\mathrm{a}}$ Tomoya Hamamatsu, ${ }^{\mathrm{a}}$ Toshiyasu Inuzuka, ${ }^{\mathrm{b}}$ Masaki Takahashi, ${ }^{\mathrm{a}}$ Hidemi Yoda* ${ }^{\mathrm{a}}$ \\ ${ }^{a}$ Department of Materials Science, Faculty of Engineering, Shizuoka University, 3-5-1 Johoku, Naka-ku, Hamamatsu, Shizuoka 432- \\ 8561, Japan.
}

${ }^{\mathrm{b}}$ Division of Instrumental Analysis, Life Science Research Center, Gifu University, 1-1 Yanagido, Gifu 501-1193, Japan.

Fax: +81(53)4781150.

E-mail: tchyoda@ipc.shizuoka.ac.jp.

Received:

\begin{abstract}
A concise and versatile syntheses of 11-16 membered macrolides and 13-15 membered macrolactams have been achieved using a Tsuji-Trost type reaction. This approach is composed of intramolecular cyclization employing ethyl carbonate with carboxylic acids and catalytic amount of $\mathrm{Pd}\left(\mathrm{PPh}_{3}\right)_{4}$ to form carbon-heteroatom covalent bonds with no use of stoichiometric reagents.
\end{abstract}

Key words: macrolactones, macrolactams, palladiumcatalyzed reaction, carbon-heteroatom bond-formation

Macrocyclic lactones so-called macrolides are important molecules in biological and medicinal chemistries, because they often show notable bioactivities as represented by erythromycins ${ }^{1}$ and epothilones. $^{2}$ In addition, their intriguing structures have also attracted considerable attention from the synthetic community, and numerous efforts have been devoted to synthesize macrolides and their derivatives. ${ }^{3}$ The conventional synthetic approaches constructing macrolides involve carbon-oxygen bond formation by the use of condensing agents such as bis(4-pyridyl)disulphide (PySSPy), ${ }^{4} \quad$ 2,4,6trichlorobenzoyl chloride, ${ }^{5}$ and 2-methyl-6nitrobenzoic anhydride (NMBA). ${ }^{6}$ Although they have been also used for the synthesis of macrocyclic natural products, it is indispensable to use stoichiometric reagents for achievement of macrolactonization.

Thus, along these lines the development of a variety of the stoichiometric macrolactonization has been accompanied up to date, ${ }^{3 a}$ however, catalytic reactions for the construction of macrolides have not so far been established. Recently, White and co-workers have reported an example of macrolactonization employing catalytic $\mathrm{Pd}(\mathrm{OAc})_{2} / \mathrm{BQ} \quad \alpha$-olefin allylic oxidation system, expanding the utility of transition-metalcatalyzed reaction for macrocyclic carbon-oxygen bond formation. ${ }^{7}$ Considering that the reaction proceeds via a Pd-templated $\pi$-allyl carboxylate intermediate, intramolecular Tsuji-Trost type reaction with carboxylic acids bearing allylic leaving groups would be expected to afford macrolides. To the best of our knowledge, only one example of this type of reaction has been reported by Trost in his review and the catalytic synthesis remained undeveloped. ${ }^{8}$ In this paper, we report an efficient and general method for constructing 11-16 membered macrolides with $\mathrm{Pd}(0)$ catalyst and further extension of this method to the synthesis of 13-15 membered macrolactams. For the purpose of the construction of macrocycles, we use ethyl carbonate as the leaving group, because cleavage of the allylic carbon-oxygen bond in allylic carbonate would provide $\pi$-allylpalladium intermediate, readily giving rise to cyclization under base free conditions (Scheme 1).

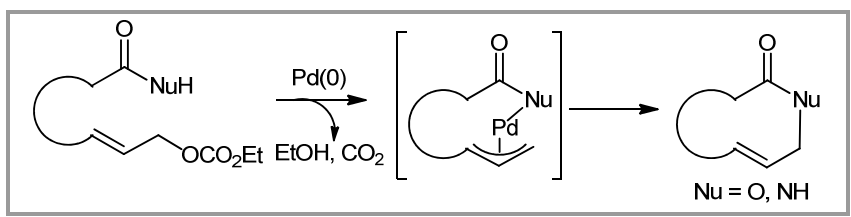

Scheme 1

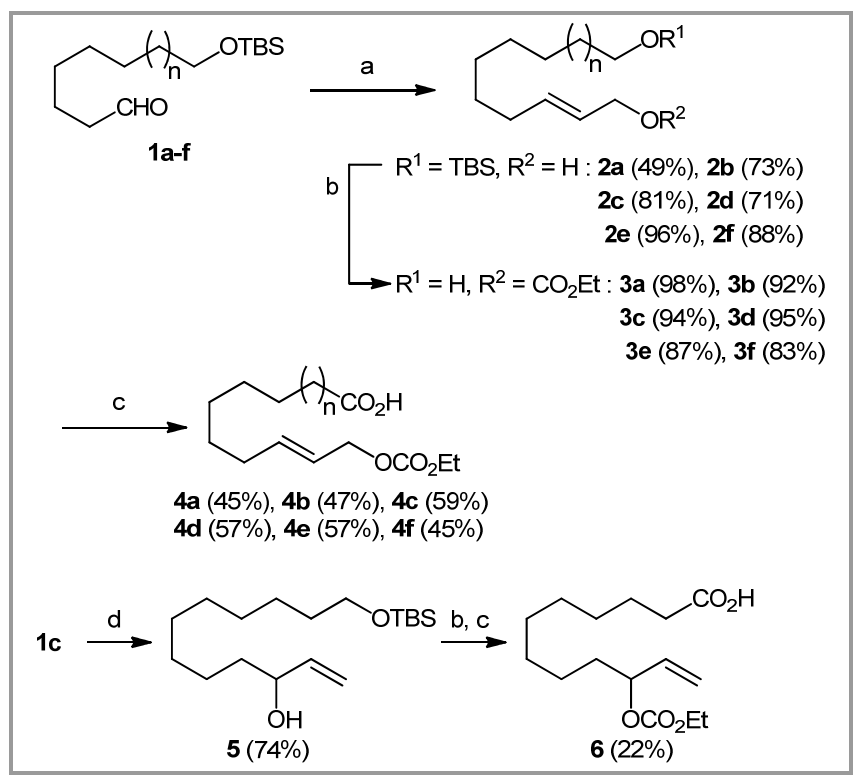

Scheme 2 Reagents and conditions: $\mathbf{a} ; \mathrm{n}=1, \mathbf{b} ; \mathrm{n}=2, \mathbf{c} ; \mathrm{n}=3$, $\mathbf{d}$; $\mathrm{n}=4$, e; $\mathrm{n}=5$, f; $\mathrm{n}=6$ : (a) (i) (EtO) ${ }_{2} \mathrm{P}(\mathrm{O}) \mathrm{CH}_{2} \mathrm{CO}_{2} \mathrm{Et}, \mathrm{t}$-BuOK, THF, $-78^{\circ} \mathrm{C}$; (ii) DIBAL-H, $\mathrm{CH}_{2} \mathrm{Cl}_{2},-78^{\circ} \mathrm{C}$; (b) (i) ethyl chlorocarbonate, pyridine; (ii) PPTS, EtOH; (c) (i) PDC, MS4Å, $\mathrm{CH}_{2} \mathrm{Cl}_{2}$; (ii) $\mathrm{NaClO}_{2}, \mathrm{NaH}_{2} \mathrm{PO}_{4} \cdot 2 \mathrm{H}_{2} \mathrm{O}$, 2-methyl-2-butene, $t$-BuOH; (d) vinylmagnesium chloride, THF, $0^{\circ} \mathrm{C}$.

The preparation of cyclization precursors $4 \mathbf{a}-\mathbf{f}(\mathrm{n}=1$ 6) were shown in Scheme 2. Linear aldehydes ${ }^{9}$ 1a-f underwent Horner-Emmons reaction and DIBAL-H reduction to give $E$-allyl alcohols 2a-f, respectively. Allylic alcohol moieties were then converted into 
corresponding allyl ethyl carbonates followed by deprotection of TBS protecting groups to afford 3a-f, respectively. The resulting primary hydroxy groups were subsequently oxidized in a stepwise manner to give 4a-f.

Meanwhile, we also prepared regioisomeric ethyl carbonate 6. Thus, addition of vinylmagnesium chloride to 1c gave allyl alcohol 5 in $74 \%$ yield. This intermediate was readily converted to $\mathbf{6 c}$ through the same sequence as used for the synthesis of $\mathbf{4}$.

In an initial series of experiments, we examined the formation of 13-membered macrolide $\alpha-7 c$ upon treatment of $\mathbf{4 c}$ in the presence of palladium catalyst. After screening the detailed reaction conditions using a variety of phosphine-ligands and solvents, we found that the reaction using $20 \mathrm{~mol} \%$ of $\operatorname{Pd}\left(\mathrm{PPh}_{3}\right)_{4}$ in a highly diluted $\mathrm{CH}_{2} \mathrm{Cl}_{2}$ solution $(c=2.0 \mathrm{mM})$ at room temperature afforded the optimal result. Under these conditions, lactone $\alpha-7 \mathrm{c}$ was formed in $51 \%$ yield as an $E / Z$ mixture (83:17), while its regioisomer $\gamma$-7c was not at all formed from observation of its ${ }^{1} \mathrm{H}$ NMR spectroscopy (Table 1, Entry 3). ${ }^{10} \mathbf{4 b , d - f}$ also efficiently underwent the macrolactonization to generate $\mathbf{7 b}, \mathbf{d}-\mathbf{f}$ in moderate to good yields, respectively (Entries 2,4-6) with the exception that the use of $4 \mathbf{a}(n=1)$ resulted in a low-yield formation of desired $\alpha-7 \mathbf{a}$ with a substantial amount of by-products (Entry 1). ${ }^{11}$ As a consequence, $\mathbf{7 b}$-d were given with nearly complete control of regioselectivity ( $\alpha: \gamma>97: 3$, Entries 2-4), whereas relatively mild regioselectivities were obtained for substrates $\mathbf{4 e , f}$ with a longer chain (Entries 5 and 6). The $E / Z$ ratios of $\alpha-7 \mathbf{b}-\mathbf{d}$ seem to be significantly influenced by the ring sizes, favoring $E$ isomer. It is worth noting that $\mathbf{6}$, a regioisomeric substrate of 4c, gave macrolides 7c with the almost same regio- and geometric isomer ratios as the use of 4c (Entry 7; 55\% yield, $\alpha: \gamma=99: 1, E: Z=86: 14$ ). These results indicate that the reactions occurred according to the same mechanism involving formation of the $\pi$-allylpalladium intermediate, extrusion of $\mathrm{CO}_{2}$, and intramolecular nucleophilic attack of the carboxylate.

Table 1 Pd(0)-catalyzed macrolactonization

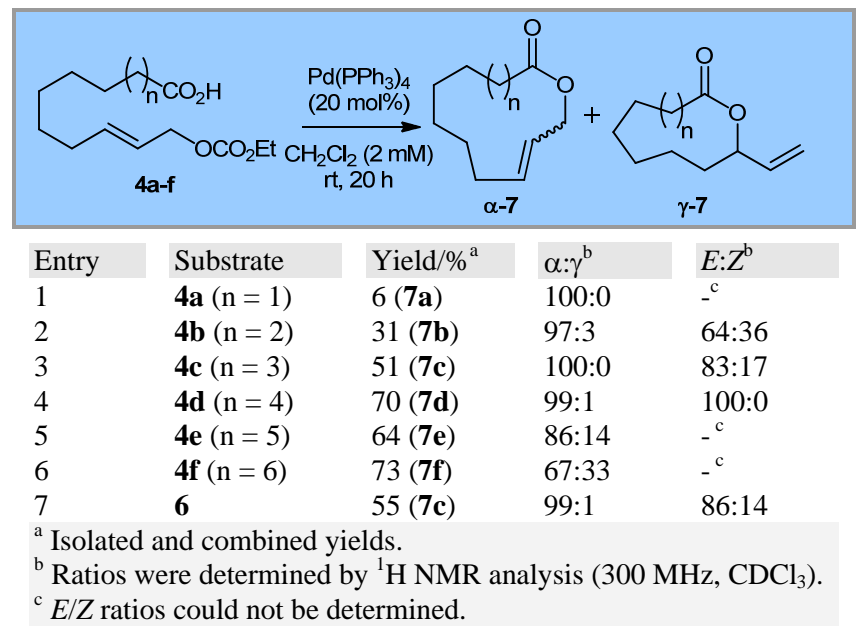

Encouraged by this successful implementation of the Pd-catalyzed macrocyclization of carboxylic acids $\mathbf{4}$, we turned our attention to the synthesis of corresponding nitrogen-containing heterocycles (Scheme 3, Table 2). Although carboxylic acid 4c could be smoothly converted to the corresponding amide 8c, subsequent attempts to perform the $\mathrm{Pd}\left(\mathrm{PPh}_{3}\right)_{4}$-catalyzed macrocyclization unfortunately resulted in decomposition of the starting material (Entry 1). Alternatively, Boc- and Cbz-protected amides $9 \mathbf{c}$ and $\mathbf{1 0 c}$ prepared from $\mathbf{8} \mathbf{c}^{12}$ were found to undergo efficient macrocyclization in the presence of $\mathrm{Pd}\left(\mathrm{PPh}_{3}\right)_{4}$ and $t$-BuOK ${ }^{13}$ to give 13-membered lactams 12c and 13c with complete regioselectivities in favor of the E-isomers (Entries 2 and 3). Furthermore, 9d,e also cyclized to yield 14- and 15membered lactams 12d,e with high regioselectivities, respectively (Entries 4 and 5).

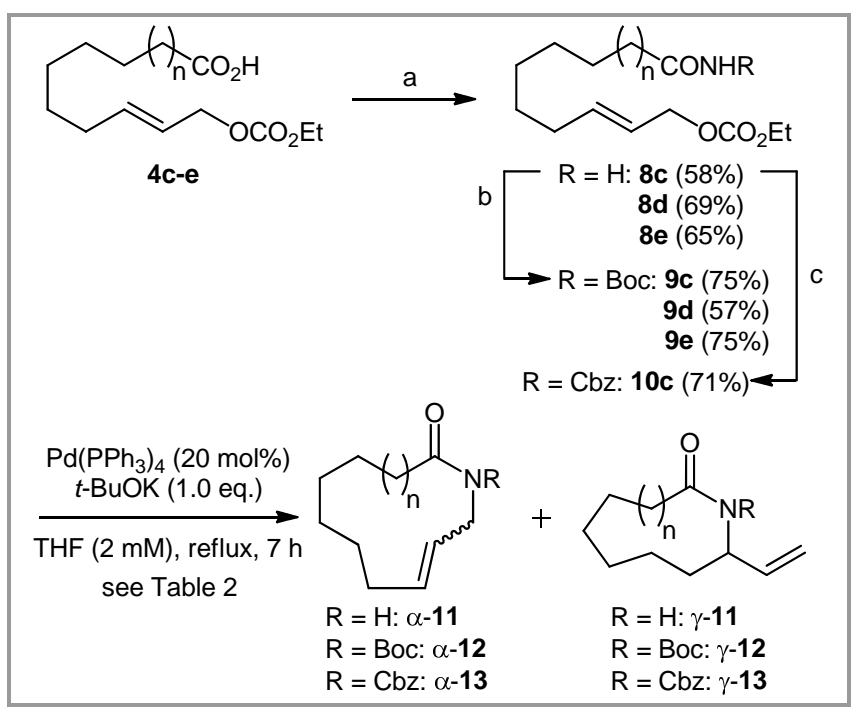

Scheme 3 Reagents and conditions: $\mathbf{c} ; n=3, \mathbf{d} ; n=4, \mathbf{e} ; n=5$ : (a) (i) DCC, HOSu, $\mathrm{Et}_{3} \mathrm{~N}, \mathrm{CH}_{2} \mathrm{Cl}_{2}$; (ii) $\mathrm{HCO}_{2} \mathrm{NH}_{4}, \mathrm{Et}_{3} \mathrm{~N}$, 1,4-dioxane; (b) $(\mathrm{COCl})_{2}, \mathrm{ClCH}_{2} \mathrm{CH}_{2} \mathrm{Cl}$, reflux, then $t-\mathrm{BuOH}, 0^{\circ} \mathrm{C}$; (b) $(\mathrm{COCl})_{2}$, $\mathrm{ClCH}_{2} \mathrm{CH}_{2} \mathrm{Cl}$, reflux, then $\mathrm{BnOH}, 0^{\circ} \mathrm{C}$.

\begin{tabular}{|c|c|c|c|c|}
\hline Entry & substrate & Yield $/ \%^{a}$ & $\alpha: \gamma^{b}$ & $E: Z^{\mathrm{b}}$ \\
\hline 1 & 8c & 0 (11c) & - & - \\
\hline 2 & 9c & 68 (12c) & 100:0 & $84: 16$ \\
\hline 3 & 10c & 68 (13c) & 100:0 & $87: 13$ \\
\hline 4 & 9d & 67 (12d) & 99:1 & $83 / 17$ \\
\hline 5 & $9 e$ & $34(\mathbf{1 2 e})$ & $95: 5$ & $73 / 27$ \\
\hline
\end{tabular}

In summary, we demonstrated the new synthetic methodology for catalytic macrocyclizations associated with carbon-oxygen and carbon-nitrogen bond formations. Compared to the conventional macrolactonizations, this approach is advantageous in that only easily removable alcohols and $\mathrm{CO}_{2}$ were formed as side-products during the course of the reactions. The success of this diverse and efficient 
macrocyclization could show broader applicability of this methodology to the synthesis of macrocyclic natural products, and, in addition, represents the first example of Pd-catalyzed macrolactamization to generate 13-15 membered lactams.

Supporting Information for this article is available online at http://www.thiemeconnect.de/ejournals/toc/synlett.

\section{Acknowledgment}

This work was supported in part by a Grant-in-Aid for Scientific Research from the Ministry of Education, Culture, Sports, Science and Technology, Japan.

\section{References}

(1) (a) Vester, B.; Douthwaite, S. Antimicrob. Agents Chemother. 2001, 45, 1. (b) Schlunzen, F.; Zarivach, R.; Harms, J.; Bashan, A.; Tocilj, A.; Albrecht, R.; Yonath, A.; Franceschi, F. Nature 2001, 413, 814; (c) Hansen, J. L.; Ippolito, J. A.; Ban, N.; Nissen, P.; Moore, P. B.; Steitz, T. A. Mol. Cells 2002, 10, 117.

(2) (a) Gerth, K.; Bedorf, N.; Hofle, G.; Irschik, H.; Reichenbach, H. J. Antibiot. 1996, 49, 560. (b) Hofle, G.; Bedorf, N.; Steinmetz, H.; Schomburg, D.; Gerth, K.; Reichenbach, H. Angew. Chem. 1996, 108, 1671; Angew. Chem. Int. Ed. Engl. 1996, 35, 1567.

(3) For recent reviews, see: (a) Parenty, A.; Moreau, X.; Campagne, J.-M. Chem. Rev. 2006, 106, 911. (b) Yeung, K.-S.; Paterson, I. Chem. Rev. 2005, 105, 4237.

(4) (a) Corey, E. J.; Nicolaou, K. C. J. Am. Chem. Soc. 1974, 96, 5614. (b) Corey, E. J.; Nicolaou, K. C.; Melvin, L. S. J. Am. Chem. Soc. 1975, 97, 653.

(5) Inanaga, J.; Hirata, K.; Saeki, H.; Katsuki, T.; Yamaguchi, M. Bull. Chem. Soc. Jpn. 1979, 52, 1989.

(6) (a) Shiina, I.; Ibuka, R.; Kubota, M. Chem. Lett. 2002, 31, 286. (b) Shiina, I.; Kubota, M.; Ibuka, R. Tetrahedron Lett. 2002, 43, 7535.

(7) (a) Fraunhoffer, K. J.; Prabagaran, N.; Sirois, L. E.; White, M. C. J. Am. Chem. Soc. 2006, 128, 9032. (b) Stang, E. M.; White, M. C. Nature Chem. 2009, 1, 547.

(8) Trost, B. M. Angew. Chem. Int. Ed. Engl. 1989, 28, 1173.

(9) (a) Liu, L.; Floreancig, P. E. Org. Lett. 2009, 11, 3152.

(b) Kim, S.; Adiyaman, Y.; Saha, G.; Powell, W. S.;

Rokach, J. Tetrahedron Lett. 2001, 42, 4445. (c) Nagano,

H.; Tada, A.; Isobe, Y.; Yajima, T. Synlett 2000, 1193.

(d) Makado, G.; Morimoto, T.; Sugimoto, Y.; Tsutsumi, K.; Kagawa, N.; Kakiuchi, K. Adv. Synth. Cat.

2010, 352, 299. (e) He, W.; Soll, C. E.; Chavadi, S. S.; Quadri, L. E. N. J. Am. Chem. Soc. 2009, 131, 16744.

(10) We observed that the reaction with the isolated single $E$ $\alpha-7 \mathrm{c}$ under the same reaction conditions afforded a 90:10 mixture of $E / Z$-isomers without production of $\gamma$ 7c (Scheme 4).

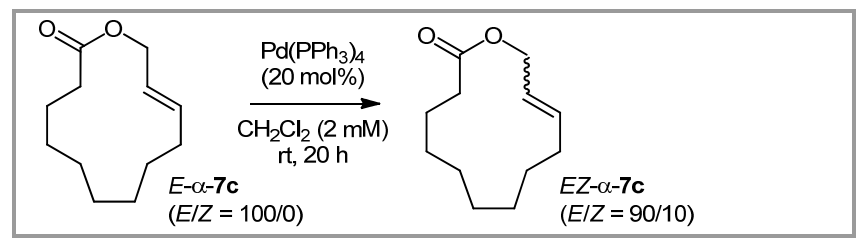

Scheme 4

(11) This would be attributed to the strain based on the ring size.
(12) Leonard, N. J.; Cruickshank, K. A. J. Org. Chem. 1985, $50,2480$.

(13) The macrolactamization of 9c in the absence of $t$-BuOK resulted in $\alpha-12 c$ in $44 \%$ yield (Scheme 5).

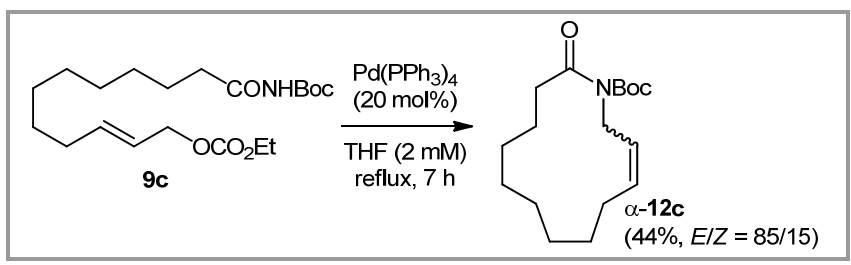

Scheme 5 
Palladium-Catalyzed Macrolactonization/Macrolactamization

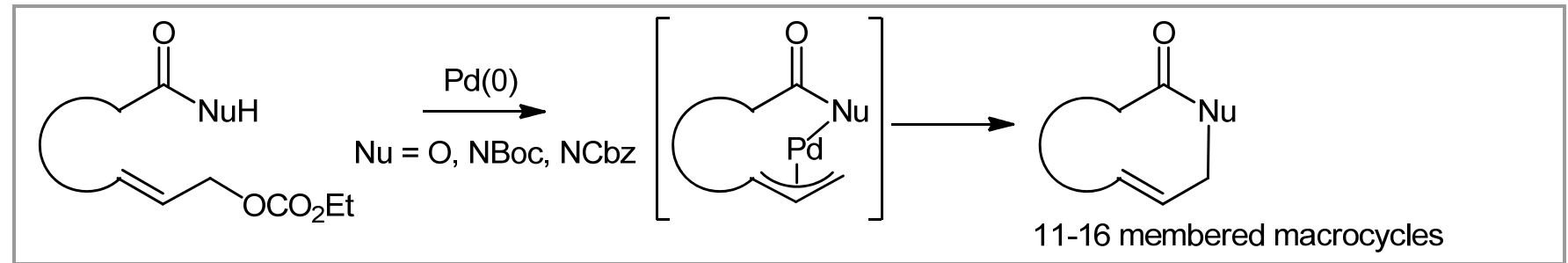

Graphical acstract 